\title{
Quantitative miRNA Expression Analysis Using Fluidigm Microfluidics Dynamic Arrays
}

Jin Sung Jang ${ }^{1}$, Vernadette A Simon², Rod M Feddersen², Fariborz Rakhshan², Debra A Schultz ${ }^{2}$, Michael A Zschunke ${ }^{3}$, Wilma L Lingle ${ }^{3}$, Christopher P Kolbert ${ }^{2}$, Jin Jen ${ }^{1,2^{*}}$

\begin{abstract}
Background: MicroRNAs (miRNAs) represent a growing class of small non-coding RNAs that are important regulators of gene expression in both plants and animals. Studies have shown that miRNAs play a critical role in human cancer and they can influence the level of cell proliferation and apoptosis by modulating gene expression. Currently, methods for the detection and measurement of miRNA expression include small and moderatethroughput technologies, such as standard quantitative PCR and microarray based analysis. However, these methods have several limitations when used in large clinical studies where a high-throughput and highly quantitative technology needed for the efficient characterization of a large number of miRNA transcripts in clinical samples. Furthermore, archival formalin fixed, paraffin embedded (FFPE) samples are increasingly becoming the primary resource for gene expression studies because fresh frozen (FF) samples are often difficult to obtain and requires special storage conditions. In this study, we evaluated the miRNA expression levels in FFPE and FF samples as well as several lung cancer cell lines employing a high throughput qPCR-based microfluidic technology. The results were compared to standard $\mathrm{qPCR}$ and hybridization-based microarray platforms using the same samples.

Results: We demonstrated highly correlated Ct values between multiplex and singleplex RT reactions in standard qPCR assays for miRNA expression using total RNA from A549 ( $R=0.98 ; p<0.0001)$ and H1299 $(R=0.95 ; p<$ 0.0001 ) lung cancer cell lines. The Ct values generated by the microfluidic technology (Fluidigm 48.48 dynamic array systems) resulted in a left-shift toward lower Ct values compared to those observed by ABI $7900 \mathrm{HT}$ (mean difference, 3.79), suggesting that the microfluidic technology exhibited a greater sensitivity. In addition, we show that as little as $10 \mathrm{ng}$ total RNA can be used to reliably detect all 48 or 96 tested miRNAs using a 96-multiplexing RT reaction in both FFPE and FF samples. Finally, we compared miRNA expression measurements in both FFPE and FF samples by qPCR using the 96.96 dynamic array and Affymetrix microarrays. Fold change comparisons for comparable genes between the two platforms indicated that the overall correlation was $R=0.60$. The maximum fold change detected by the Affymetrix microarray was 3.5 compared to 13 by the 96.96 dynamic array.

Conclusion: The GPCR-array based microfluidic dynamic array platform can be used in conjunction with multiplexed RT reactions for miRNA gene expression profiling. We showed that this approach is highly reproducible and the results correlate closely with the existing singleplex QPCR platform at a throughput that is 5 to 20 times higher and a sample and reagent usage that was approximately 50-100 times lower than conventional assays. We established optimal conditions for using the Fluidigm microfluidic technology for rapid, cost effective, and customizable arrays for miRNA expression profiling and validation.
\end{abstract}

\footnotetext{
* Correspondence: Jen.Jin@mayo.edu

'Department of Pulmonary and Critical Care Medicine, 200 First Street SW,

Rochester MN 55905, USA

Full list of author information is available at the end of the article
}

\section{() Biomed Central}

(C) 2011 Jang et al; licensee BioMed Central Ltd. This is an Open Access article distributed under the terms of the Creative Commons Attribution License (http://creativecommons.org/licenses/by/2.0), which permits unrestricted use, distribution, and reproduction in any medium, provided the original work is properly cited. 


\section{Background}

MicroRNAs (miRNAs) are short, single-stranded, noncoding RNAs that regulate gene expression by interacting with or inhibiting mRNA in both plants and animals [1-3]. To date, more than 800 human miRNAs have been identified and the total number is still increasing [4]. It is estimated that about two thirds of all protein-coding genes are regulated by miRNAs [5]. Although some miRNAs are yet to be characterized, biochemical and genetic studies have indicated that miRNA regulation is essential for biological processes such as development, differentiation, cell proliferation, and apoptosis [6-9]. Recent studies have demonstrated that miRNA genes can be aberrantly expressed in human cancers and they function as either oncogenes or tumor suppressor genes via regulation of target transcripts $[10,11]$.

Although formalin fixed, paraffin embedded (FFPE) tissue samples typically contain fragmented nucleic acids, they are the most commonly available clinical specimens for histology and pathological analysis and are a critical resource for developing new molecular markers in the cancer research $[12,13]$. Because of their small size, miRNA molecules appear to be less prone to degradation, in contrast to mRNA expression studies, and no significant differences in miRNA expression between FFPE and FF samples have been observed [14-16].

Real-time quantitative PCR (qPCR) is considered a 'gold standard' for quantification of gene expression and has been widely employed as a validation method for microarray studies. However, the qPCR method is a relatively low throughput, high cost, and tedious technique typically performed in a 96 or 384 well plate format. The Fluidigm microfluidic technology uses the integrated fluidic circuits (IFC) which contain tens of thousands of microfluidic controlled valves and interconnected channels to move molecules of biological samples and reagents in a variety of patterns [17]. IFCs reduce a qPCR reaction from the routine 10-20 microliter volume down to a 10 nanoliter scale making it possible to perform routine qPCR analysis for thousands of reactions in a single run. This technology has been used for gene expression, genotyping, mutation detection, and absolute quantization of nucleic-acid sequences $[17,18]$. Spurgeon et al. [19] showed that microfluidic dynamic arrays can be used to simultaneously measure 48 mRNAs in several tissues. Wang et al. [20] developed a high throughput SNP genotyping assay demonstrating high accuracy and call rate in human samples using a nanofluidic platform. This new real-time PCR technology makes it possible to perform validation as well as high throughput gene expression measurements using very limited sample and reagent quantities $[17,19]$.

Here we show that miRNA expression profiling and validation are possible using high throughput real-time quantitative PCR (qPCR) method with the microfluidic technology. FFPE and FF samples appear to perform similarly in this platform when cDNA are generated from 96 multiplexed RT reactions. We compared this new approach to the standard microarray-based technology. To our knowledge, this study is the first report comparing miRNA expression profiling between microarrays and qPCR using microfluidic arrays.

\section{Results}

\section{Correlation of Reverse Transcription Efficiency between Single- and Multiplexed Primer Sets}

To evaluate the efficiency of reverse transcription (RT) reactions using different number of primer, we first compared the use of a single miRNA specific primer and an 11 primer-mixed set using 100 ng total RNA isolated from A549 (Figure 1A) and H1299 lung cancer cells (Figure 1B). After the RT reaction, a pre-amplification PCR was performed for 10 cycles and qRT-PCR was carried out using individual TaqMan probes for all 11 genes. Results in Figure 1 showed a strong correlation of $\mathrm{Ct}$ values between the two conditions with correlation coefficients at 0.98 and 0.95 , respectively, for A549 and H1299 cell lines.

\section{Reproducibility of Expression Levels between 48.48 Dynamic Arrays and ABI 7900 HT}

As an initial evaluation to determine miRNA expression by using 48.48 dynamic array, we tested its reproducibility by comparing $\mathrm{Ct}$ values observed between ABI 7900 HT and Fluidigm dynamic array system using FF samples. Fourteen out of 16 miRNA targets exhibited lower Ct values in the microfluidics 48.48 dynamic array system compared to those obtained by standard qPCR using the ABI $7900 \mathrm{HT}$ (Figure 2A \&2B). The mean $\mathrm{Ct}$ values between the platforms were $12.48( \pm 0.49)$ for the 48.48 dynamic array and $16.21( \pm 0.82)$ for the ABI $7900 \mathrm{HT}$ (coefficient of variance $\mathrm{CV}=0.08$ and 0.06 , respectively) reflecting a significantly increased

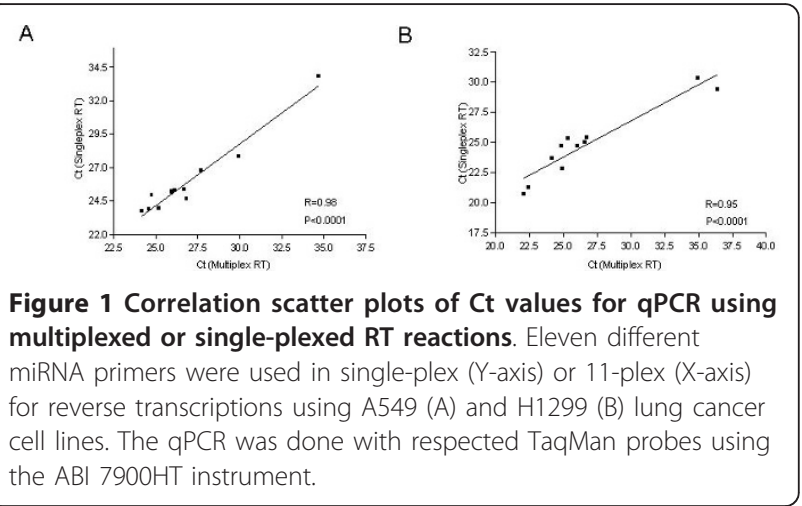




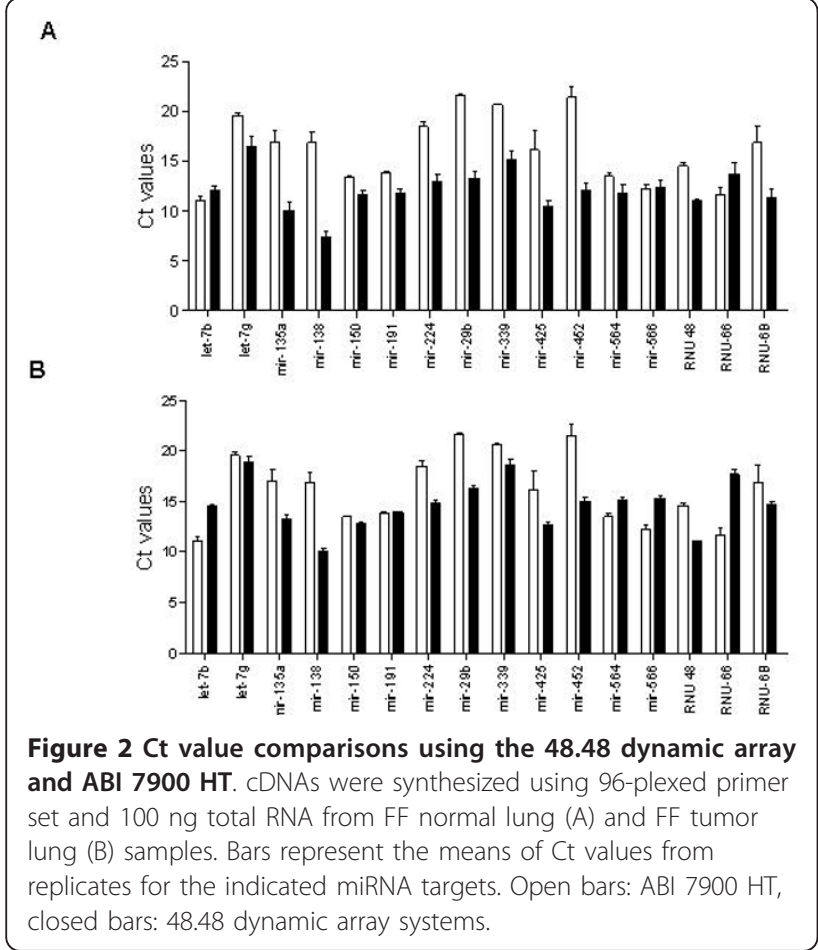

sensitivity by the microfluidics array when qPCR reactions are being carried out in nanoliter volumes.

\section{Comparison of miRNA Expression between FF and FFPE Samples}

We next used both ABI 7900 HT and Fluidigm 48.48 dynamic array to directly compare the qRT-PCR performance using RNA from FF and FFPE samples over a wide range of miRNA gene expression levels. The cDNA was synthesized using a 96-plex primer set and $100 \mathrm{ng}$ of total RNA from both sample types. The Ct values of FFPE samples ranged from 13 to 25 while those of FF samples ranged between 11 to 22 on the standard ABI platform with correlations at $\mathrm{R}=0.95$ and 0.87 , respectively, $\mathrm{p}<0.0001$ ) (Figure $3 \mathrm{~A} \& 3 \mathrm{~B}$ ). When the same reaction were carried out using the 48.48 dynamic arrays, FFPE samples had similarly higher average $\mathrm{Ct}$ values compared to $\mathrm{FF}$ samples reflecting the generally lower quality of the RNA in FFPE samples (6.84-22.6 in FFPE vs. 6.49-20.97 in FF). Again, the Ct values from both sample types were highly correlated (Figures $3 \mathrm{C}$ and $3 \mathrm{D}$ ).

\section{Effect of RNA Template Concentration Using $\mathbf{4 8 . 4 8}$ Dynamic Arrays}

To evaluate the dynamic range of the multiplex RT-PCR in the 48.48 dynamic array systems, we evaluated the $\mathrm{Ct}$ values for each miRNA target using total input RNA quantities at $10 \mathrm{ng}, 25 \mathrm{ng}, 50 \mathrm{ng}$ or $100 \mathrm{ng}$ per reaction.

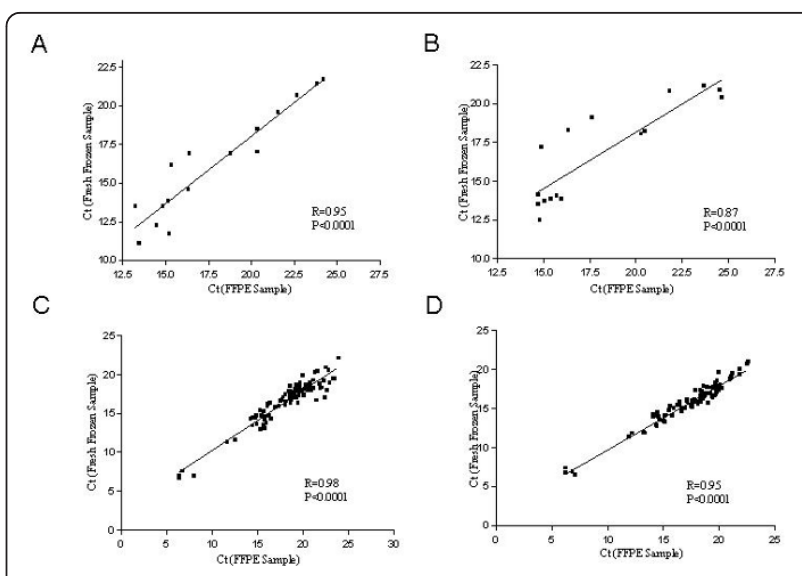

Figure 3 Correlation between matched FFPE and FF samples in qPCR by $A B I$ vs $\mathbf{4 8 . 4 8}$ dynamic array platforms. CDNAs were synthesized using 96-plex primer sets and RNA from both normal lung ( $A$ and $C$ ) and lung tumor samples ( $B$ and $D)$. QPCR reactions were carried out individually for 16 miRNA targets ( $A$ and $B$ ) by $A B I$ $7900 \mathrm{HT}$, and for 48 miRNA targets by the 48.48 dynamic array (C and D). Each plot displays mean values calculated from triplicate samples.

The reverse transcription and pre-amplification were carried out in 96-plex format and the qPCR were run using 48.48 dynamic arrays. The scatter plots shown in Figure 4 demonstrates that the correlation coefficients were essentially the same over the tested range of input RNA for both FF (Figure 4A \&4B) and FFPE samples
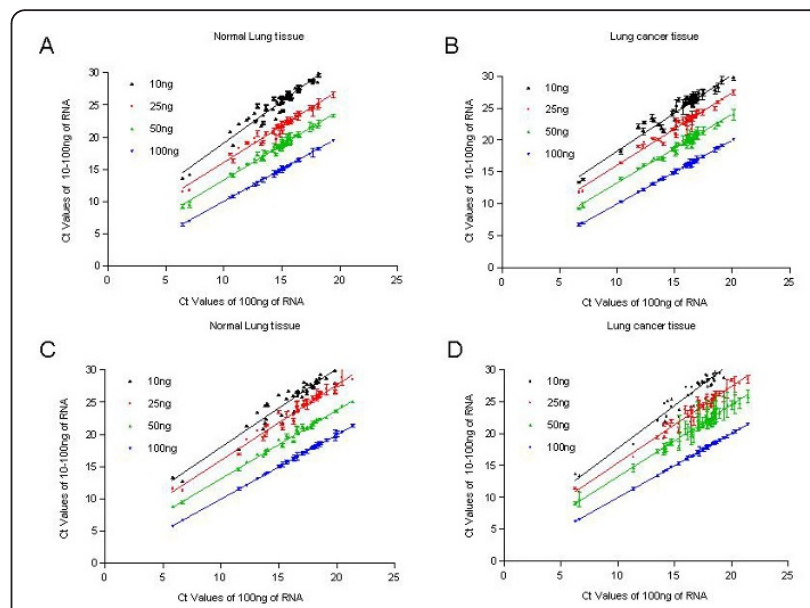

Figure 4 Effect of in put RNA concentrations on Ct values. A total of 48 miRNAs were tested using different input amounts of total RNA from FFPE and FF samples for RT and QPCR by the 48.48 dynamic array systems. The Ct values were plotted using the average of the duplicated measurements and the error bar for values on Y-axis. Correlation scatter plots represent the correlation of Ct values for $100 \mathrm{ng}$ RNA (X-axis) and the Ct values for the same FF (A and B) or FFPE (C and D) sample at $10 \mathrm{ng}$ to $100 \mathrm{ng}$ concentrations ( $Y$-axis). 
(Figure 4C \&4D) with the lowest correlation at $\mathrm{R}=0.96$ $(\mathrm{p}<0.0001)$.

\section{Comparison of miRNA Expression between the 96.96 Dynamic Array and Affymetrix GeneChip microRNA Microarray}

We compared miRNA expression levels measured by the 96.96 dynamic array with those obtained from the Affymetrix miRNA GeneChip ${ }^{\mathrm{TM}}$. The same samples, FF1 and FFPE9 analyzed by the 96.96 dynamic array were subjected to gene expression profiling using the Affymetrix miRNA arrays. In the Affymetrix miRNA array analysis, 33-35\% of miRNA targets were detectable in each sample with a correlation of $\mathrm{R}=0.99$. Similarly, strong correlations were also obtained using the 96.96 dynamic array when replicate RNA samples were analyzed $(\mathrm{R}=$ 0.95). This high correlation value was consistent across both FF and FFPE sample types (Table 1). Overall, the miRNA microarray profiles generated for FFPE and FF samples showed high correlations across all 847 human miRNAs $(R=0.94, p<0.0001$, data not shown). Similarly, the $\mathrm{Ct}$ values above detection threshold were obtained for 86 (FF) and 80 (FFPE) of 94 miRNA targets by the qPCR-based analysis using microfluidics. Fiftynine probes that were called present on Affymetrix miRNA array matched those tested by the 96.96 dynamic array. Comparison of the fold changes between the two samples obtained by Fluidigm and Affymetrix arrays showed an overall correlation of $R=0.60$. Significantly, the fold changes detected by Affymetrix microarray ranged between 0 to 3.5, while those by Fluidigm ranged between 0 to 13 reflecting a much higher dynamic range by the microfluidics platform (Figure 5).

\section{Discussion}

MicroRNAs are potential biomarkers and novel targets for cancer diagnosis, prognosis and recurrence $[10,11,21]$. Conventional methods for detection and

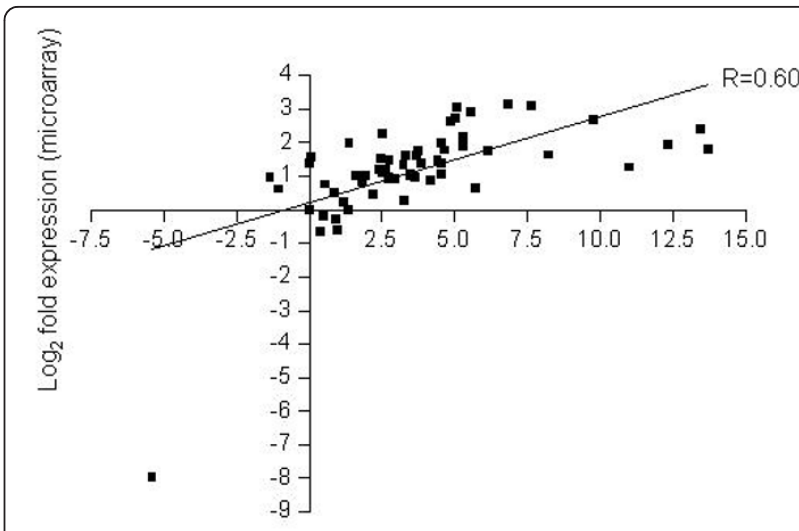

$\log _{2}$ fold expression (96.96 dynamic array)

Figure 5 miRNA expression measurements by Fluidigm dynamic array and Affymetrix microarray. The raw intensity values of microarray data were transformed to $\log _{2}$ values for comparison to PCR Ct values generated by the qPCR platform. Gene expression differences between FF and FFPE were compared against 59 shared genes. Fold differences by the dynamic array $\left(\log _{2}\right)$ were calculated by $\triangle \Delta C t$ method; $\Delta C t=$ (target miRNA $\log _{2}$ values-hsa-mir-16 $\log _{2}$ value), $\Delta \Delta \mathrm{Ct}=$ (fresh frozen $\Delta \mathrm{Ct}$-FFPE $\Delta \mathrm{Ct}$ ).

characterization of miRNAs during clinical investigations sometimes fall short because of low throughput, insufficient sensitivity, and relatively high cost. The recently developed Microfluidic technology enables a significantly higher throughput qPCR analysis for a large number of samples; and assays in a much shorter time and at a lower cost compared to the conventional methods [17]. This new real-time PCR technology can be used to perform experimental validation as well as high throughput gene expression measurement with nearly 100 -fold less input of sample and reagent $[17,19]$. In this study, we examined miRNA expression measurements using qPCR-based microfluidic technology using FFPE and matched FF samples. We evaluated this relatively high throughput miRNA profiling method using

Table 1 Comparison of gene expression measurements between Affymetrix microarray and Fluidigm 96.96 dynamic array.

\begin{tabular}{|c|c|c|c|c|c|c|c|c|c|}
\hline \multirow[t]{2}{*}{ Platform } & \multirow[t]{2}{*}{ Sample $^{\dagger}$} & \multicolumn{2}{|c|}{ Background } & \multirow[t]{2}{*}{ Signal to Noise } & \multicolumn{3}{|c|}{ Positive Signal Intensity or $\mathrm{Ct}$} & \multirow[t]{2}{*}{ Detection Rate (\%) } & \multirow[t]{2}{*}{ Replicate Correlation } \\
\hline & & $\overline{A V E}$ & MAX & & MIN & MAX & AVE & & \\
\hline \multirow{4}{*}{$\begin{array}{l}\text { Microarray } \\
\text { (847 miRNA) }\end{array}$} & FF\#1a & 2.66 & 15.79 & 189 & 3.49 & 10530 & 503 & 33 & 0.997 \\
\hline & $\mathrm{FF \# 1b}$ & 2.66 & 11.68 & 185 & 1.73 & 10313 & 493 & 33 & \\
\hline & FFPE\#9a & 2.26 & 35.38 & 208 & 2.34 & 9331 & 470 & 35 & 0.996 \\
\hline & FFPE\#9b & 2.22 & 17.85 & 209 & 2.59 & 8724 & 464 & 35 & \\
\hline \multirow{4}{*}{$\begin{array}{l}96.96 \text { dynamic array } \\
\text { (94 miRNA) }\end{array}$} & FF\#1a & N/A & N/A & - & 7.9 & 22.4 & 16.7 & 91 & 0.954 \\
\hline & FF\#1b & N/A & N/A & - & 5.0 & 22.7 & 16.2 & 91 & \\
\hline & FFPE\#9a & N/A & N/A & - & 5.9 & 35.9 & 19.5 & 85 & 0.956 \\
\hline & FFPE\#9b & N/A & N/A & - & 4.2 & 34.9 & 19.0 & 85 & \\
\hline
\end{tabular}

\footnotetext{
${ }^{+}$Samples are as described in the method; N/A, not applicable.
} 
the standard TaqMan miRNA assays on ABI 7900 HT and the Fluidigm microfluidic dynamic arrays. We also developed and validated miRNA expression assays using cDNA made from either singleplex or multiplex RT reactions and assessed their application for highthroughput miRNA profiling using the microfluidic dynamic arrays.

TaqMan ${ }^{\circledR}$ assays are traditionally used for validation of microarray-based expression analysis [13,22-25]. The RT primer in each $\operatorname{TaqMan}^{\circledR}$ miRNA assay is a singlestranded stem-loop RT primer which was developed to allow cDNA detection to be more specific and sensitive as compared to conventional linear primer reverse transcription [22]. Based on this result, Chen, et al. suggested that stem-loop RT primers can be used for multiplex RT reaction and small RNA cloning for better efficiency and specificity $[22,24]$. In our study, the absolute $\mathrm{Ct}$ for miRNA expression levels by singleplex were slightly lower than those obtained in multiplex conditions, but both methods showed high correlation compared to results of the qRT-PCR (A549 cells, $\mathrm{R}=0.98$ and H1299 cells, $\mathrm{R}=0.95 ; \mathrm{p}<0.0001$ ) (Figure 1 ).

Several studies have demonstrated that FFPE samples can be used for miRNA profiling analysis [13,16]. However, most of the studies are based on microarray data and validated using low throughput Applied Biosystems qPCR platforms $[13,15,16]$. Here, we compared the correlation of miRNA expression profiles between FFPE and matched FF samples using both qPCR and array bases platforms. We observed a high correlation of miRNA expression levels $(\mathrm{R}=0.95$ and $\mathrm{R}=0.98$; $\mathrm{p}<$ 0.0001 ) measured for both sample types using the ABI $7900 \mathrm{HT}$ and the 48.48 dynamic array (Figure 3). FF samples appeared to contain higher levels of miRNAs than FFPE samples in our study, consistent with results observed by Leite, et al [13] using standard qPCR assays. This could be due to the loss of miRNA during paraffin embedding process or RNA extraction. Considering the minimal influence on miRNA measurements, the small difference of $\mathrm{Ct}$ values between FFPE and FF samples is not expected to affect the result of the study, particularly for Fluidigm based studies since the reference miRNA targets are measured on the same array for the exact same sample.

To compare between qPCR platforms, we investigated 16 different miRNA targets using both ABI 7900 HT and Microfluidic technology with FF RNA samples. The $\mathrm{Ct}$ value of the 48.48 dynamic array system shifted toward lower $\mathrm{Ct}$ values compared to those observed by $\mathrm{ABI} 7900 \mathrm{HT}$ in a $5 \mu \mathrm{l}$ reaction. In our hands, the mean $\mathrm{Ct}$ value difference was 3.79 between the two systems and the coefficient of variation across the 128 reactions in the 48.48 dynamic array system was $8.9 \%$ (Figure 2). In addition, we showed that as little as $10 \mathrm{ng}$ of total
RNA could be used to detect all 48 miRNAs with 96multiplexing RT reaction in both FFPE and FF samples (Figure 4). The minimal correlation coefficient observed was 0.96 for $10 \mathrm{ng}$ vs.100 ng input RNA for both FF and FFPE samples $(\mathrm{P}<0.0001)$. Lao et al. [24] suggested that $10 \mathrm{ng}$ of a human lung sample can be assessed with a substantial degree of accuracy without statistical variations from stochastic effects when multiplex RT reactions are employed. Therefore, our data are consistent with those previously reported and indicates that 96multiplexed miRNA RT reactions can provide reliable miRNA profiles when using low input amounts in the dynamic array systems. Although just a few samples were used in this study, the robustness of the assay was demonstrated consistently for all tested assays varying at a wide range of $\mathrm{Ct}$ values (Figures 3 and 4).

To determine the concordance between qPCR-arrays and microarrays, we compared miRNA expression using 96.96 dynamic arrays and the hybridization-based miRNA array offered by Affymetrix. We used the same samples for both analyses and the overall correlation for the 59 shared genes was $\mathrm{R}=0.60$ ( $\mathrm{p}<0.0001$ ) for miRNA expression between the two platforms. This moderate correlation likely reflects the use of fundamentally different principles for gene expression measurements in these two platforms. Fluidigm uses the quantitative PCR assays which are highly sensitive with a dynamic range of at least 6-7 logs $[19,22]$. In contrast, Affymetrix GeneChip is primarily based on hybridization of the labeled probes to the matching oligonucleotides that are affixed to a matrix. The dynamic range of the microarray is usually 3 to 4 logs $[25,26]$. In our hands, the maximum fold change observed was around 3 for Affymetrix arrays and 13 for Fluidigm dynamic array (Figure 5).

Several studies have previously reported a similar rate of inter-platform concordance among different miRNA microarrays and the different expression values from each miRNA microarray platform when compared to qPCR values [27-29]. Although highly sensitive, the quality of the gene expression assessment by the TaqMan-based method is dependent largely on the specificity of the probe to discriminate among highly conserved miRNA target sequences as well as the sensitivity of the assay probes to quantitatively measure the target miRNA over a wide range of expression levels. The small 18-25 nucleotide length of the miRNA targets creates a challenge to meet these requirements. Pradervand, et al. [27] observed that the different GC content of mature miRNA sequences contributes to higher difference values between both Affymetrix and qPCR. This same study also showed a lower correlation between qPCR and Affymetrix while reporting a higher correlation between $\mathrm{qPCR}$ based assay and other platforms ( $\mathrm{R}$ $=0.8-0.9$ ). In the study by Chen, et al. [29], a correlation 
of 0.44 ( $\mathrm{p}<0.0001, \mathrm{~N}=84$ ) was reported between TaqMan qPCR-array and microarray. The variation observed was thought to result from the low abundance miRNAs reflecting the different sensitivities of the two platforms. Therefore, the assessment of miRNA expression in a given system should be interpreted with caution and it requires validation using at least two different platforms when the correlation is poor or the expression level of the target is low.

\section{Conclusion}

We demonstrated that multiplexing $\mathrm{RT}$ reactions with stem-loop primers can be adapted with relative ease to a new qPCR-array based microfluidic platform to profile miRNA expression profiling. We showed that this approach is highly reproducible and correlates closely with standard ABI7900 systems yet offers higher throughput, with much lower sample input, and reagent usage. We believe that the microfluidic dynamic array technology could be used to develop cost effective and customized assays with rapid turn-around for profiling and validating of miRNA expression.

\section{Methods}

RNA extraction from FFPE, FF samples and lung cancer cell lines

FF and corresponding FFPE samples were obtained from lung cancer (FF1 and FFPE9) or non-diseased lung tissues (FF4 and FFPE7) that had been preserved between 2007 and 2008 following the approved Mayo Clinic Institutional Review Board protocol. FFPE samples were cut to $10 \mu \mathrm{m}$ thickness and several tissue slices were put into a $1.5 \mathrm{ml}$ tube. One milliliter of xylene was added for deparaffinization followed by mixing twice with a high speed vortex for $3 \mathrm{~min}$ at room temperature. Total RNA was then extracted with the Qiagen miRNeasy FFPE kit (Valencia, $\mathrm{CA}$ ) and/or RecoverAll (Ambion Inc. Austin, TX) following manufacturers' protocols. Fresh-frozen tissues were extracted using Qiagen miRNeasy kit (Valencia, CA) following manufacturer's protocols. The isolation procedure for FF and FFPE samples were performed in duplicate to derive samples FF1a and FF1b, and FFPE9a and FFPE9b. Human lung cancer cell lines H1299 and A549 were cultured in RPMI 1640 growth media with 10\% fetal bovine serum and $1 \%$ penicillin $(50 \mathrm{IU} / \mathrm{mL})$ and streptomycin $(50$ $\mu \mathrm{g} / \mathrm{ml}$ ). Total RNA was isolated from TRIzol (Invitrogen, Carlsbad, CA). RNA quantity was determined using Nanodrop (Thermo Scientific, Waltham, MA) and the quality was assessed by Agilent 2100 Bioanalyzer (Agilent Technologies, Santa Clara, CA).

\section{MicroRNA reverse transcription}

The $15 \mu \mathrm{l}$ reverse transcription reaction contained $2 \mu \mathrm{l}$ of either $5,12.5,25$ or $50 \mathrm{ng} / \mu \mathrm{l}$ of total RNA, $0.2 \mu \mathrm{l}$ of
$100 \mathrm{nM}$ dNTP, $0.2 \mu \mathrm{l}$ of RNase inhibitor $20 \mathrm{U} / \mu \mathrm{l}, 1.5 \mu \mathrm{l}$ of reverse transcriptase $(50 \mathrm{U} / \mu \mathrm{l}), 8 \mu \mathrm{l}$ of 11 -or 96 -plex reverse primer (mixed to allow a final concentration of $0.05 \mathrm{X}$ of each) and $1.6 \mu \mathrm{l}$ of $\mathrm{H}_{2} \mathrm{O} .2 \mu \mathrm{l}$ of $5 \mathrm{ng}$ of total RNA and $3 \mu \mathrm{l}$ of $5 \mathrm{X}$ reverse primer were used in the single-plex RT reaction. All reagents were purchased from Applied Biosystems, Inc. (Foster City, CA). The reaction mixture was mixed with RNA and incubated as follows; $16^{\circ} \mathrm{C}$ for $30 \mathrm{~min}, 42^{\circ} \mathrm{C}$ for $30 \mathrm{~min}$ and then $85^{\circ}$ $\mathrm{C}$ for $5 \mathrm{~min}$. A list of all 96 tested assays is available upon request. The 11 primer set that was used for the RT reaction included: RNU66, RNU6B, mir-135a, mir564, mir-29b, mir-339, mir-138, mir-425, mir-191, let-7 $\mathrm{g}$ and mir-566 (Applied Biosytems, Foster City, CA).

\section{Pre-PCR amplification}

For pre-amplification of cDNA, we pooled 11 - or 96 TaqMan Assays at a final concentration of $0.2 \mathrm{X}$ for each assay. Pre-PCR amplification reaction was done at $10 \mu \mathrm{l}$ containing $5 \mu \mathrm{l}$ TaqMan PreAmp Master Mix (2X), 2.5 $\mu \mathrm{l}$ of 11 - or 96-pooled TaqMan assay mix $(0.2 \mathrm{X})$ and $2.5 \mu \mathrm{l}$ of cDNA. The pre-amplification PCR performed at one cycle $95^{\circ} \mathrm{C}$ for $10 \mathrm{~min}, 10$ cycles at $95^{\circ} \mathrm{C}$ for 15 sec and then $60^{\circ} \mathrm{C}$ for $4 \mathrm{~min}$. After pre-amplification PCR, the product was diluted 1:5 with $\mathrm{dH}_{2} \mathrm{O}$ and stored at $-80^{\circ} \mathrm{C}$ until needed.

\section{Real-time qPCR}

qRT-PCR was carried out using ABI 7900 HT Real-time PCR system in a 384 well plate format. PCR reaction of $5 \mu \mathrm{l}$ contained $2.5 \mu \mathrm{l}$ of TaqMan PCR Master Mix-UNG (2X), $0.25 \mu \mathrm{l}$ of each TaqMan assay probe (20X), $1.25 \mu \mathrm{l}$ of diluted cDNA and $1 \mu \mathrm{l}$ of $\mathrm{H}_{2} \mathrm{O}$. The PCR was performed at $95^{\circ} \mathrm{C}$ for $10 \mathrm{~min}$, followed by 40 cycles at $95^{\circ}$ $\mathrm{C}$ for $15 \mathrm{sec}$ and $60^{\circ} \mathrm{C}$ for $1 \mathrm{~min}$. The data was analyzed with ABI RQ Manager software (Foster City, CA) after exportation as a SDS file.

\section{miRNA expression analysis using 48.48 and 96.96 dynamic array}

Reverse transcription was carried out as described above using pooled miRNA primers with $10 \mathrm{ng}, 25 \mathrm{ng}, 50 \mathrm{ng}$ and $100 \mathrm{ng}$ of total input RNA. Pre-amplification was performed with a 96 pooled (final $0.2 \mathrm{X}$ of each) TaqMan assay. After pre-amplification PCR, the product was diluted $1: 5$ with $\mathrm{dH}_{2} \mathrm{O}$ and stored in $-80^{\circ} \mathrm{C}$ until needed. qPCR was carried out using the 48.48 or 96.96 dynamic array (Fluidigm Corporation, CA, USA) following the manufacturer's protocol [19]. Specifically, a $5 \mu \mathrm{l}$ sample mixture was prepared for each sample containing $1 \times$ TaqMan Universal Master Mix (No UNG), $1 \times$ GE Sample Loading Reagent (Fluidigm PN 85000746) and each of diluted pre-amplified cDNA. $5 \mu \mathrm{l}$ of Assay mix was prepared with $1 \times$ each of TaqMan miRNA 
assay and $1 \times$ Assay Loading Reagent (Fluidigm PN 85000736). An IFC controller was used to prime the fluidics array (chip) with control line fluid and then with samples and assay mixes in the appropriate inlets. After loading, the chip was placed in the BioMark Instrument for PCR at $95^{\circ} \mathrm{C}$ for $10 \mathrm{~min}$, followed by 40 cycles at $95^{\circ}$ $\mathrm{C}$ for $15 \mathrm{sec}$ and $60^{\circ} \mathrm{C}$ for $1 \mathrm{~min}$. The data was analyzed with Real-Time PCR Analysis Software in the BIOMARK instrument (Fluidigm Corporation, CA, USA).

\section{miRNA microarray}

The miRNA microarray profiling was performed using Affymetrix GeneChip miRNA arrays (Santa Clara, CA, USA) according to manufacturer's recommended protocol. Briefly, $1 \mu \mathrm{g}$ of total RNA was labeled by polyA polymerase addition using the Genisphere FlashTag HSR kit following the manufacturer's recommendations (Genisphere, Hatfield, PA). RNA was hybridized to the Affymetrix miRNA array as recommended by the vendor. Standard Affymetrix array cassette staining, washing and scanning was performed using the post-hybridization kit (\#900720; Affymetrix) and GeneChip Scanner 3000. Feature extraction was performed using Affymetrix Command Console software. The raw data were treated by the following workflow: background detection, RMA global background correlation, quantile normalization, median polish and $\log 2$-transformed with miRNA QC tool software (Affymetrix).

\section{Statistical Analysis}

Statistical Analysis was performed using GraphPad Prism 4 (GraphPad Software, Inc.). The Pearson correlation coefficient(R) was employed to determine the correlation of efficiency of $\mathrm{RT}$ reaction and expression of FFPE and FF samples.

\section{Acknowledgements}

We thank Stacy Johnson and Cindy Dilworth for editorial assistance and Drs. Julie Cunningham and Eric Wieben for scientific input. This work is supported by funds from Mayo Cancer Center and the Center for Individualized Medicine.

\section{Author details}

${ }^{1}$ Department of Pulmonary and Critical Care Medicine, 200 First Street SW, Rochester MN 55905, USA. ${ }^{2}$ Gene Expression Shared Resource, Advanced Genomics Technology Center and the Mayo Clinic Cancer Center, 200 First Street SW, Rochester MN 55905, USA. ${ }^{3}$ Department of Experimental Pathology, 200 First Street SW, Rochester MN 55905, USA.

\section{Authors' contributions}

JSJ performed the research, analyzed the data and wrote the paper. VS, RMF, FR and DS participated in the Fluidigm and/or microarray experiments. MZ performed RNA preparation and WL participated in study discussions. JJ directed research and analyzed the data. RMF, CPK and JJ revised the manuscript. All authors read, corrected and approved the final manuscript.

Received: 13 May 2010 Accepted: 9 March 2011

Published: 9 March 2011
References

1. Ambros V: The functions of animal microRNAs. Nature 2004 431(7006):350-355.

2. Bartel DP, Chen CZ: Micromanagers of gene expression: the potentially widespread influence of metazoan microRNAs. Nature reviews 2004, 5(5):396-400.

3. Lim LP, Lau NC, Garrett-Engele P, Grimson A, Schelter JM, Castle J, Bartel DP, Linsley PS, Johnson JM: Microarray analysis shows that some microRNAs downregulate large numbers of target mRNAs. Nature 2005, 433(7027):769-773.

4. Bentwich I, Avniel A, Karov Y, Aharonov R, Gilad S, Barad O, Barzilai A, Einat $P$, Einav $U$, Meiri $E$, et al: Identification of hundreds of conserved and nonconserved human microRNAs. Nature genetics 2005, 37(7):766-770

5. Friedman RC, Farh KK, Burge CB, Bartel DP: Most mammalian mRNAs are conserved targets of microRNAs. Genome research 2009, 19(1):92-105.

6. Cheng AM, Byrom MW, Shelton J, Ford LP: Antisense inhibition of human miRNAs and indications for an involvement of miRNA in cell growth and apoptosis. Nucleic acids research 2005, 33(4):1290-1297.

7. Karp $X$, Ambros V: Developmental biology. Encountering microRNAs in cell fate signaling. Science (New York, NY) 2005, 310(5752):1288-1289.

8. Sempere LF, Sokol NS, Dubrovsky EB, Berger EM, Ambros V: Temporal regulation of microRNA expression in Drosophila melanogaster mediated by hormonal signals and broad-Complex gene activity. Developmental biology 2003, 259(1):9-18.

9. Xu P, Guo M, Hay BA: MicroRNAs and the regulation of cell death. Trends Genet 2004, 20(12):617-624

10. Calin GA, Croce CM: MicroRNA signatures in human cancers. Nat Rev Cancer 2006, 6(11):857-866.

11. Esquela-Kerscher A, Slack FJ: Oncomirs-microRNAs with a role in cancer. Nat Rev Cancer 2006, 6(4):259-269.

12. Lehmann $U$, Kreipe $\mathrm{H}$ : Real-time PCR analysis of DNA and RNA extracted from formalin-fixed and paraffin-embedded biopsies. Methods (San Diego, (alif) 2001, 25(4):409-418

13. Leite KR, Canavez JM, Reis ST, Tomiyama AH, Piantino CB, Sanudo A Camara-Lopes LH, Srougi M: miRNA analysis of prostate cancer by quantitative real time PCR: Comparison between formalin-fixed paraffin embedded and fresh-frozen tissue. Urologic oncology 2009.

14. Mortarino M, Gioia G, Gelain ME, Albonico F, Roccabianca P, Ferri E, Comazzi S: Identification of suitable endogenous controls and differentially expressed microRNAs in canine fresh-frozen and FFPE lymphoma samples. Leukemia research 2009, 34(8):1070-7.

15. Xi Y, Nakajima G, Gavin E, Morris CG, Kudo K, Hayashi K, Ju J: Systematic analysis of microRNA expression of RNA extracted from fresh frozen and formalin-fixed paraffin-embedded samples. RNA (New York, NY) 2007, 13(10):1668-1674.

16. Zhang X, Chen J, Radcliffe T, Lebrun DP, Tron VA, Feilotter H: An arraybased analysis of microRNA expression comparing matched frozen and formalin-fixed paraffin-embedded human tissue samples. J Mol Diagn 2008, 10(6):513-519.

17. Melin J, Quake SR: Microfluidic large-scale integration: the evolution of design rules for biological automation. Annual review of biophysics and biomolecular structure 2007, 36:213-231.

18. Thorsen T, Maerkl SJ, Quake SR: Microfluidic large-scale integration. Science (New York, NY) 2002, 298(5593):580-584.

19. Spurgeon SL, Jones RC, Ramakrishnan R: High throughput gene expression measurement with real time PCR in a microfluidic dynamic array. PloS one 2008, 3(2):e1662.

20. Wang J, Lin M, Crenshaw A, Hutchinson A, Hicks B, Yeager M, Berndt S, Huang WY, Hayes RB, Chanock SJ, et al: High-throughput single nucleotide polymorphism genotyping using nanofluidic Dynamic Arrays. BMC genomics 2009, 10:561.

21. Johnson SM, Grosshans H, Shingara J, Byrom M, Jarvis R, Cheng A, Labourier $E$, Reinert KL, Brown D, Slack FJ: RAS is regulated by the let-7 microRNA family. Cell 2005, 120(5):635-647.

22. Chen C, Ridzon DA, Broomer AJ, Zhou Z, Lee DH, Nguyen JT, Barbisin M Xu NL, Mahuvakar VR, Andersen MR, et al: Real-time quantification of microRNAs by stem-loop RT-PCR. Nucleic acids research 2005, 33(20): e179.

23. Lao K, Xu NL, Sun YA, Livak KJ, Straus NA: Real time PCR profiling of 330 human micro-RNAs. Biotechnology journal 2007, 2(1):33-35. 
24. Lao K, Xu NL, Yeung V, Chen C, Livak K, Straus NA: Multiplexing RT-PCR for the detection of multiple miRNA species in small samples.

Biochemical and biophysical research communications 2006, 343(1):85-89.

25. Tang F, Hajkova P, Barton SC, O'Carroll D, Lee C, Lao K, Surani MA: 220-plex microRNA expression profile of a single cell. Nature protocols 2006, 1(3):1154-1159.

26. Shippy R, Sendera TJ, Lockner R, Palaniappan C, Kaysser-Kranich T, Watts G, Alsobrook J: Performance evaluation of commercial short-oligonucleotide microarrays and the impact of noise in making cross-platform correlations. BMC genomics 2004, 5(1):61.

27. Pradervand $\mathrm{S}$, Weber J, Lemoine $\mathrm{F}$, Consales F, Paillusson $\mathrm{A}$, Dupasquier $\mathrm{M}$, Thomas J, Richter H, Kaessmann H, Beaudoing E, et al: Concordance among digital gene expression, microarrays, and qPCR when measuring differential expression of microRNAs. BioTechniques 2010, 48(3):219-222.

28. Sato F, Tsuchiya S, Terasawa K, Tsujimoto G: Intra-platform repeatability and inter-platform comparability of microRNA microarray technology. PloS one 2009, 4(5):e5540.

29. Chen Y, Gelfond JA, McManus LM, Shireman PK: Reproducibility of quantitative RT-PCR array in miRNA expression profiling and comparison with microarray analysis. BMC genomics 2009, 10:407.

doi:10.1186/1471-2164-12-144

Cite this article as: Jang et al:: Quantitative miRNA Expression Analysis

Using Fluidigm Microfluidics Dynamic Arrays. BMC Genomics 2011 12:144.

\section{Submit your next manuscript to BioMed Central} and take full advantage of:

- Convenient online submission

- Thorough peer review

- No space constraints or color figure charges

- Immediate publication on acceptance

- Inclusion in PubMed, CAS, Scopus and Google Scholar

- Research which is freely available for redistribution

Submit your manuscript at www.biomedcentral.com/submit
Biomed Central 